\title{
Comments on Lucy Allais, Manifest Reality: Kant's Idealism and his Realism
}

\section{Ralph Walker}

Lucy's book is very interesting and very illuminating. It has made me think deeply about many things I thought I was sure about. I have found myself agreeing with Lucy a great deal of the time, and sometimes where I disagree I am not certain how substantive the disagreement is. I should like to speak up in defence of noumena, and also to question the claim that the argument for transcendental idealism rests squarely on the Aesthetic, with no real contribution from what follows. In both these cases, though, I am inclined to think that Lucy's account shows us what Kant ought to have meant, I am just not convinced that it was what he did mean.

In general I think Lucy's account of what transcendental idealism amounts to is clear and convincing. Taking off from Kant's own description of it in the Prolegomena, as extending Locke's thought about secondary qualities to all the other qualities we can be aware of, she takes him as holding them to be "essentially manifest qualities", qualities that are "features of the way objects appear to us, and nothing but such features” (p.117). ${ }^{1}$ This appearing, however, is relational, grounded in the way things are in themselves. All we can know about things as they are in themselves is that they are, somehow, the grounds of our perceiving things in the way we do. Appearances are "the mind-dependent way something mindindependent is presented to us” (p.133). This seems to me absolutely right, but I want to argue that given Kant's other assumptions it entails "noumenalism”, the thesis that things are, in themselves, intelligibilia. But as it stands it is neutral as to whether the case for transcendental idealism does or does not rest entirely on the Transcendental Aesthetic.

Nobody can deny that Kant does believe the Aesthetic provides a sufficient ground for transcendental idealism. The question is whether his account of synthesis, and of the large part it necessarily plays in cognition, provides a second, and potentially independent, case for it. Lucy thinks it does not. In her view his concerns about synthesis make no case for idealism; they are as important for a realist as for a transcendental idealist. His arguments are conditional, designed to show that the application of a priori concepts like those of object and cause is a necessary condition of empirical concept application. She sees him as securing their application to the spatio-temporal world, along with the a priori principles related to them, by drawing on the already-established doctrine of transcendental idealism (pp.285ff., 299f.).

What Kant argued in the Aesthetic was that cognition is possible for human beings only through the pure intuitions of space and of time. It seems to me that the argument in the Analytic is parallel. Cognition is possible for us only if we apply the concepts of cause, object, actuality, and so on to our experience. These concepts are a priori concepts: there is no guarantee that they apply to things in themselves, indeed no reason to think that they do. Yet they give us truths, truths about the world of appearances. These truths do indeed depend upon what is given to us empirically, but all that is given to us empirically is regularity; the truths about objects and causes, implying as they do a necessity which goes well beyond constant conjunction, can hold within the empirical reality that is knowable to us because, 
and only because, that empirical reality just is the world as it appears to us. It has to appear to us in this way, as governed by causal necessity, and it therefore is this way in the empirically real world, because that is how things have to appear to us given the conditions under which alone human cognition is possible. If that is right, the requirement to apply the categories, and to apply them in the specific ways Kant argues for, constitutes a case for transcendental idealism which is distinct from that made in the Aesthetic. The truth, for example, that all alterations have causes is itself transcendentally ideal.

There is a related view, which a realist might hold and which Kant does not hold. That is, that although Kant is right to say that these concepts are indispensable to us, they carry with them no guarantee of applicability, but have fortunately turned out to be methodologically useful. This might be just a lucky accident, or perhaps the product of evolution, but neither way would we be entitled to claim truth for our statements about objects and causes. This position would be rather like van Fraassen's constructive empiricism. ${ }^{2}$ If Kant had adopted it, he would only have been claiming that we must think of the world as ordered in such a way that every alteration has a cause, not that this must actually be so. And indeed, one can argue that this is all he is really entitled to claim, because every law must hold universally if is is to be a law at all, whereas no possible experience could ever establish a nomically universal truth. But this is clearly not the position he did adopt, because it collapses his distinction between constitutive and regulative principles. Constitutive principles ${ }^{3}$ are principles which are true of appearances, whereas regulative principles tell us how we ought to think about things. He wants to hold that there are truths about empirical laws, within the world of appearances; even though to claim something is a universal law one must really be relying on regulative principles, since the claim goes beyond the limits of possible experience. Indeed, it his insistence that the Second Analogy expresses truths about appearances that makes so problematic for him the reconciliation of free will with rigorous determinism; and in the second Critique as well as the first, he is vehement in his assertion of that determinism (A 550/B 578; V:99).

As Lucy's account makes entirely clear, in applying (for example) the concept of cause we are dependent on there being patterns of regularity in our experience, patterns which in turn must depend on the unknowable character of things as they are in themselves. That means that we still do need the lucky accident, the correspondence of the way we think about things with the underlying reality. Things in themselves must so affect us as to produce what we see as continuing constant conjunctions - continuing not just over periods of past observation but into the indefinite future. The lucky accident is not removed by Kant's claims about laws. Indeed, he seems to be making that point himself at the end of the Entdeckung, when he says we can never explain why sensibility should provide this patterning, even though without it experience would not be possible (VIII:249f).

Part of my ground for thinking that the Analytic gives us an independent case for transcendental idealism is that Kant insists that these truths must hold within the world of appearances, instead of saying that there are certain ways in which we must think and which yield results that often turn out useful. But it is only part of my ground, though the other part depends on understanding the synthesis of apprehension differently from Lucy. If she is right about that this second part disappears, but the first one should not, being independent of it. 
I entirely agree with Lucy in "attributing to Kant the thought that the only way an object that exists independently of our representing it could be directly present to consciousness would be through affecting us” (p.199). The data of sense must clearly be received with intrinsic characteristics of their own, or they could not provide the material for any kind of synthesis. But the question is whether they directly reach consciousness in that form, or whether we can be aware of them only as the products of a category-governed synthesis. If the 'I think' can accompany all my representations, a matter on which Kant seems to be quite definite, they must be capable of being synthesised together, but that does not make them the products of synthesis. However, to be representations at all they must be spatio-temporal, or at least temporal; and Kant at times seems to be saying that this requires a synthesis which must be constitutive of the features under which we can be aware of them. Lucy argues against that: intuition by itself gives us particular shapes, colours, etc., presented as located in space and in time. "[A] manifold of outer intuition is an immediately presented array of distinct, spatiotemporally located and related particulars” (p.170). It seems to me, though, that Kant thinks the synthesis of apprehension is required to transform whatever is received by our minds into something spatio-temporally arrayed. In A the synthesis of apprehension is clearly in some sense prior to the synthesis of recognition, and is needed to represent temporal succession and to unite the manifold together in one representation, of which we can be aware (A 99). In B it is called "the composition of the manifold in an empirical intuition, through which perception, i.e., empirical consciousness of it (as appearance), becomes possible” (B 160). So " a combination with which everything that is to be represented as determined in space or time must agree, is already given a priori, along with (not in) these intuitions” (B 161). "Consequently all synthesis, through which even perception itself becomes possible, stands under the categories” (B 161). This at least seems to me the task assigned, if somewhat obscurely, to the synthesis of apprehension.

One might reasonably ask whether this doesn't amount to unnecessary complication. Lucy's account, one might think, captures all that Kant needs, and makes everything a lot clearer. However these remarks of his do seem to tell in favour of the more complicated view of things. And unless he holds something like that, I find it hard to see how there can be Axioms of Intuition and Anticipations of Perception. As Lucy says, the section on Axioms of Intuition seeks to show how mathematics can have objective validity (p.191), but it does this by arguing that we can represent spatial and temporal magnitudes only by synthesising them in accordance with the categories of Quantity, so that anything represented in space and time must be synthesised in the same way - enabling us to be aware of sizes and shapes. The section on the Anticipations argues that every sensation must have some degree of intensive magnitude, which is itself the product of a synthesis, this time in accordance with the categories of Quality. Only so can we have sensations of colour, taste, warmth, and so on. Kant stresses that there is a crucial element of the empirical here, and of course that has to be so since we are being affected by things as they are in themselves. But the characteristics that affect us cannot be quite the characteristics we are aware of, whether consciously or indeed self-consciously, since as they are in themselves they have no degree of intensity, no size, no shape, no spatial location and no place in time.

If we were transcendental realists about the intuitions of space and time themselves, rejecting the Aesthetic but accepting the arguments of the Analytic so far as they are compatible with that rejection, these arguments would not be seriously affected. Our direct intuition of a real, 
Newtonian space and a real, Newtonian time would still, if Kant is right, need conceptual synthesis in order for us to be able to represent spatial and temporal magnitudes, and so to be aware of sizes and shapes; and conceptual synthesis would still be required for us to represent sensations as having intensive magnitude. So I think we have a second argument to the conclusion that purely conceptual considerations can provide a case for transcendental idealism, as Kant understands the matter.

Now: what can we say about the way things are in themselves? Can we call them noumena? Kant often does, of course. But there are also texts that seem to rule noumena out, leaving us only with the negative conception of a noumenon as that of "a thing insofar as it is not an object of our sensible intuition, because we abstract from the manner of our intuition of it" (B 307). And calling something a noumenon in anything more than this negative sense might well seem to imply that we know something about its nature, contrary to one of Kant's most central claims.

Unsurprisingly, much depends on what we understand the word "noumenon" to mean, and on what "noumenalism" therefore amounts to. Lucy describes noumenalism as a commitment to the existence of non-sensible, non-spatio-temporal intelligibilia (p.7): noumenalists hold that intelligibilia exist in addition to the spatio-temporal appearances of which we have knowledge, and are unknowable by us. Now certainly Kant discourages us from speculating about intelligible worlds (B 311, A 289/B 345), and from claiming theoretical knowledge beyond the limits of possible experience. So, if things are, in themselves, intelligibilia, our minds cannot cognize them. But it doesn't seem to me that Kant's distinction between the positive and negative understandings of "noumenon" is meant to come to anything more than this. Things are perhaps complicated by the fact that "noumenon", or more accurately voov́ $\mu \varepsilon v o v$, is a Greek past participle, and therefore ambiguous between "thing grasped by reason" and "thing that could be grasped by reason”. For part of Kant's objection to accepting noumena in the positive sense is that the term can be understood to imply that there exists a rational being that grasps such things (A 252, B 307). He wants to make clear both that we are not such beings ourselves, and that we have no grounds - at least in theoretical philosophy - for supposing that there is any such being at all. Such a being would have to be an intellectual intuition, the possibility of which is problematic (A 256/B 311f.). Thus in A, where he uses "noumenon" very much in the way that in B he uses "noumenon in the positive sense", he describes noumena as "things that are merely objects of the understanding and that, nevertheless, can be given to an intuition, though not to sensible intuition (as present to an intellectual intuition)” (A 249: my emphasis, and my translation of the last three words, coram intuitu intellectuali). As usual B is clearer than A, but in B it is clear that to recognise things as appearances requires us to admit that there must be a way things are in themselves, and we tend to slip into taking this "entirely indeterminate concept" of a noumenon as the determinate concept of a being that we could somehow come to cognize intellectually.

Setting aside these confusing texts, it seems to me that it would not only be consistent, but required by Lucy's general account of transcendental idealism, to accept that things as they are in themselves are intelligibilia, voov́ $\mu \varepsilon v \alpha$, in the sense that they could be grasped by reason, not in the sense that they actually are grasped by reason - certainly not by ours, nor by an intellectus intuitus since there may be no such thing. So far as I can see, to accept this would be to adopt noumenalism, as Lucy characterizes it. 
What she most objects to in noumenalism seems to be the idea that noumena are things of an entirely different kind from the things we can see and feel (p.76). But it is central to her own position that there is a way things are in themselves, and that (because space and time are transcendentally ideal) the way they are in themselves is not spatio-temporal. Now, some people say that things as they are in themselves can be identified with things as they appear to us in space and time, and other people deny that they can be identified and must be regarded as distinct. Lucy spends some time defending a moderate version of the former view (pp.716, 242f.). The dispute seems to me empty: there is a difference of pictures here, and some people find one picture more congenial than the other, but there is no way in which the pictures can be filled out and given content. Spatio-temporal things are identified in terms of their spatio-temporal locations, and it is unclear what it could mean to identify spatiotemporal entities with entities outside space and time, or even to raise the question about identity and distinctness. ${ }^{4}$ But this need not detain us here: for whatever position one takes on the identity issue, Kant plainly holds that things affect our senses, and therefore the way things are in themselves must affect our senses, even if we may be able to understand this affecting only in terms of the unschematized category of cause. The way things are in themselves grounds the way things appear in space and time, but since space and time are transcendentally ideal the only way things can be in themselves is a non-spatio-temporal way.

Are they then "things of an entirely different kind from the things we can see and feel"? Yes and no: they are different in that they are not spatio-temporal; on the other hand there is a sense in which they are the things we see and feel. Except of course we can only see and feel them in their spatio-temporal guise, and can only identify them under that spatio-temporal guise, and we can know nothing about whatever identities and differences there may be among them as they are in in themselves. At one point Lucy also characterises noumena as "objects which are not spatio-temporal and which do not interact with the senses" (p.61), but I do not know of any noumenalist who would deny that things in themselves ground appearances; indeed it would be very difficult to attribute any such view to Kant, as of course Lucy recognizes.

The reason things in themselves have to be intelligibilia is that there is nothing else they could be. We order appearances through the forms of our intuition, space and time. Beings with different forms of intuition could no more be aware than we are of things as they are in themselves, and for the same reason. For such beings, "the manifold for intuition must already be given prior to the synthesis of understanding and independently from it” (B145). Such beings would have to order appearances in whatever ways their forms of intuition required, and they would have to synthesise them in accordance with the categories. For them as for us, cognition is possible only by "bringing the synthesis of the manifold that is given ... in intuition from elsewhere to the unity of apperception” (ibid.). Kant is quite explicit in saying that the argument of the Deduction, at least up to §20, applies to them as well.

So things in themselves cannot be things as they could be cognized by beings with any form of sensible intuition, our own or another. For Kant that leaves only one possibility. They must be the sort of beings that could be cognized by an intellectual intuition, if there were one. He regards the idea of an intellectual intuition as problematic, and reading B145 one might get the impression that it would have to be a mind like God's, for which there could be no distinction between the apprehension and the object apprehended. In that case, indeed, God might seem to be the only candidate for being such an intellect, since as Kant says this lack of 
distinction is due to the fact that for God to think an object is the very same thing as to create it. However he does on other occasions countenance the idea that there might be other intellectual intuitions than God's; and of course the idea is not an unfamiliar one. Besides Hegel's use of it, there is also Plato's apprehension of the Form of the Good, and Descartes' clear and distinct perception. Both Plato and Kant think of this as a rational grasp of something, but not through any process of reasoning, rather by direct insight, the metaphor of sight being very much in mind - just as it is in Kant's Anschauung. The implicit visual comparison is one we might find problematic nowadays, though it was in vogue not so long ago, as the idea that we have a direct and immediate awareness of our sense-data and of our inner mental states. For Kant himself, of course, that awareness could not really be unmediated, since the manifold has to be ordered in inner sense. But it can often seem unmediated, and thus serve as a model for how rational insight could work.

An intellectual intuition would apprehend things directly as they are in themselves. Since it is an intellectual intuition, pure voiv, , its objects cannot be anything else but the objects of voṽ noumena. It is true that a question might be raised about the legitimacy of applying the term "intellectual", or "rational", to this sort of intuition. It could be suggested that it might better have been just called non-sensible intuition, avoiding any implication that there might be anything rational about the ordering and arrangement of things as they are in themselves. But we have to recognize that it is Kant himself who repeatedly uses the term "intellectual intuition”, and insofar as we are trying to understand Kant's own position, he must be seen as committed to whatever that term may imply.

Plato and Hegel both have a justification for using words like "rational" and "intellectual” for such insight. For both of them, this insight can come only after a process of dialectical reasoning, and however much their conceptions of dialectic may differ it is clear that in both cases it is a rational process. So it seems appropriate to call its outcome a rational insight. For Descartes that is not so, but rather the other way round: the clear and distinct perceptions provide the indispensable basis of all reasoning and hence of rational scientia. For Kant, neither of these justifications applies, and one might question why he gives the title "intellectual" to this immediate insight into how things are in themselves. If that title is inappropriate, one need not think of that insight as voñs, or of its objects - the things in themselves - as noumena.

Since so far as I can see Kant has no good ground for using the title "intellectual” here, there is a sense in which I can agree with Lucy after all: things as they are in themselves should not be assumed to be noumena, even though Kant does make that assumption. One can take this further, and ask why he takes so much for granted the laws of logic, and analytic truths. We can't think without the laws of logic (II:82). But we can't do without the forms of intuition and the categories either, and the forms of intuition and the categories are taken, for that reason, to belong to our Gemüt and so to be determinant of appearances, not of how things are in themselves. Why not say the same of the most basic logical laws? Perhaps a being with non-sensible intuition might just be directly aware of how things are, without having to use logical thinking or anything like it. Kant does not envisage this possibility.

Nor does he envisage the possibility that things might have a way they are in themselves, without this way they are in themselves being graspable by any mind at all, even in principle. Others besides Kant have been reluctant to admit that there can be facts about reality that no 
mind of any kind could ever know, even in principle - whatever "in principle" means. Michael Dummett would be one recent example among many. ${ }^{5}$ But why shouldn't there be such facts? Kant should have asked that question. If he had, he could have recognised that the way things are in themselves may be simply beyond the cognitive powers not only of an intellectus intuitus but of any being at all. If he had recognised that, he could have seen, again, that there is no ground for thinking that things are, in themselves, noumena. However, he did not recognise that; and the unwarranted assumptions he was working with required him to hold that they are indeed noumena. So I think Lucy should recognize that he is a noumenalist, even though he shouldn't have been.

\footnotetext{
${ }^{1}$ Page references in this form are to Lucy Allais, Manifest Reality (Oxford: Oxford University Press, 2015). References to Kant's works are to the Akademie edition, by volume and page number, except in the case of the Critique of Pure Reason, where I use the customary A/B page references.

2 Bas C. van Fraassen, The Scientific Image (Oxford: Oxford University Press, 1980).

${ }^{3}$ Constitutive of experience; he does call the Analogies and the Postulates regulative in another sense, in so far as we deploy them as rules for determining what objects there are in the world of appearances (A 180/B 222f.; A 664/B 692)), but this is quite a different matter.

${ }^{4}$ James Van Cleve, Problems from Kant (New York: Oxford University Press, 1999), pp.149f. See also my

'Kant on the Number of Worlds', British Journal for the History of Philosophy 18:5 (2010).

${ }^{5}$ M.A.E. Dummett, Thought and Reality (Oxford: Oxford University Press, 2006).
} 